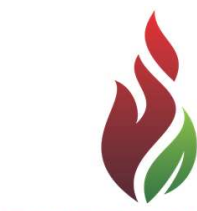

SUSTENERE

Publishing Corporation

\section{CARACTERIZAÇÃO DAS UNIDADES DE CONSERVAÇÃO DE PROTEÇÃO INTEGRAL DO ESTADO DE SERGIPE}

\section{RESUMO}

Atualmente o principal instrumento utilizado em grande parte do mundo para a preservação e conservação do patrimônio natural, assim como dos seus recursos, é a criação de áreas legalmente protegidas. As Unidades de Conservação (UCs) estabelecidas pelo SNUC são divididas em dois grandes grupos: Proteção Integral e Uso Sustentável, os quais se expandem e são estabelecidas de acordo com a relevância da conservação e o contexto da região escolhida. $O$ trabalho foi realizado em cinco unidades de conservação de Proteção Integral do Estado de Sergipe e teve como objetivo geral, caracterizar as Unidades de Proteção Integral do Estado de Sergipe, e como objetivos específicos descrever a situação atual de cada uma, avaliando sua a efetividade de manejo. A avaliação da efetividade de gestão das unidades de conservação foi adaptada da metodologia RAPPAM (Rapid Assessment and Prioritization of Protected Area Management). Constatou-se que as Unidades de Conservação de Proteção Integral do âmbito estadual possuem maior nível satisfatório de manejo em comparação as UCs do âmbito federal. A única UC municipal do Estado pode ser considerada 'Parque de Papel', já que é apenas uma área cercada sem nenhuma perspectiva de manejo.

PALAVRAS-CHAVES: Efetividade; Manejo; SNUC; Parque de Papel; Sergipe.

\section{CHARACTERISTICS OF THE INTEGRAL PROTECTED AREAS OF SERGIPE STATE}

\section{ABSTRACT}

Currently the main instrument used in much of the world for the preservation and conservation of the natural heritage as well as its resources, is the creation of legally protected areas. Conservation Units (CUs) established by SNUC are divided into two major groups: Integral Protection and Sustainable Use, which expand and are set according to the importance of conservation and the context of the chosen region. The study was conducted in five conservation units of integral protection of the State of Sergipe and had as main objective is to characterize the Integral Protection Units of the State of Sergipe, and specific objectives describe the current situation of each assessing the effectiveness of their management. The evaluation of management effectiveness of protected areas has been adapted from RAPPAM methodology (Rapid Assessment and Prioritization of Protected Area Management). It was found that the Conservation Units of Integral Protection statewide have more satisfactory level of management compared PAs federal level. The only municipal UC state can be considered 'paper park', as it is only surrounded with no prospect management area.

KEYWORDS: Effectiveness; Management; SNUC; Park Paper; Sergipe.
Revista Ibero-Americana de

Ciências Ambientais, Aquidabã, v.6, n.2, Jun, Jul, Ago, Set, Out, Nov 2015.

ISSN 2179-6858

SECTION: Articles

TOPIC: Gestão Ambiental

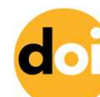

DOI: 10.6008/SPC2179-6858.2015.002.0009

Débora Joice da Silva Ferreira
Universidade Tiradentes, Brasil http://lattes.cnpq.br/9949486959788238 debora.joice@hotmail.com

Igor Azevedo Souza Universidade Tiradentes, Brasil http://lattes.cnpq.br/7991318024602851 igorbiologia1990@gmail.com

Natali Oliveira Santos Eckert Universidade Tiradentes, Brasil http://lattes.cnpq.br/4765294031240384 natalieckert mma@hotmail.com

Andressa Sales Coelho Universidade Tiradentes, Brasil http://lattes.cnpq.br/3082143845730215 andscoelho@yahoo.com.br

Received: 19/04/2015

Approved: $21 / 10 / 2015$ Reviewed anonymously in the process of blind peer.

\section{Referencing this:}

FERREIRA, D. J. S.; SOUZA, I. A.; ECKERT, N. O. S. COELHO, A. S.. Caracterização das unidades de conservação de proteção integral do estado de Sergipe.

Revista Ibero-Americana de Ciências Ambientais,

Aquidabã, v.6, n.2, p.121-143, 2015. DOI: http://dx.doi.org/10.6008/SPC21796858.2015 .002 .0009 


\section{INTRODUÇÃO}

O progresso da humanidade sempre esteve relacionado em grande parte com a exploração dos recursos naturais e a intensa urbanização e expansão agrícola seguida por exploração insustentável resultaram em impactos como a perda e a fragmentação de habitats, que são hoje grandes ameaças para a biodiversidade do Planeta (TABARELLI \& GASCON, 2005 ARAUJO, 2007). O Brasil possui grande diversidade de fitofisionomias, ambientes naturais e uma alta taxa de diversidade biológica e endemismos (RYLANDS \& BRANDON, 2005). Seus Biomas vêm sofrendo com ações antrópicas devastadoras, que já levaram a destruição de mais da metade da área original da Mata Atlântica e do Cerrado, consideradas duas regiões criticamente ameaçadas devido ao seu alto índice de endemismos (MITTERMEIER et al., 2005). A Caatinga, bioma exclusivamente brasileiro, teve cerca de $80 \%$ dos seus ecossistemas modificados, principalmente por meio de desmatamentos e queimadas (PORTELA, 2014).

Atualmente a estratégia mais empregada em todo o mundo para a preservação e conservação do patrimônio natural, assim como dos seus recursos, é a criação de áreas legalmente protegidas (FONSECA et al., 1997; DIAS, 2009; BENSUSAN, 2006). Porém, este instrumento de não se torna eficaz quando não há conhecimento prévio, planejamento e gestão efetiva, uma vez que somente seu estabelecimento por completo pode garantir a efetividade dos serviços ecossistêmicos associados a cada área protegida alcançando os objetivos da conservação (PRIMACK \& RODRIGUES, 2001; FARIA, 2004; SALMONA et al., 2014). Deste modo, grande parte dessas áreas protegidas em todo o mundo são destinadas a própria sorte, sendo criadas, mas nunca implantadas, não havendo nenhuma perspectiva ou diretriz para o seu manejo efetivo. Neste caso são denominadas "Parques de Papel” (TERBORGH \& SCHAIK 2002, DOUROJEANNI, 2013).

O Brasil provavelmente é o campeão na criação de decretos de Unidades de Conservação com reconhecimento internacional (DOUROJEANNI, 2013). As áreas brasileiras foram inicialmente legalizadas no antigo Código Florestal pelo Decreto 23.793, de 23 de janeiro de 1934 o qual criou o Parque Nacional de Itatiaia, cujos objetivos iniciais foram incentivar a pesquisa científica e oferecer lazer para as populações urbanas (MEDEIROS et al., 2004). De acordo com Dias (2009), desde a década de 1990 vem ocorrendo uma ampliação da área territorial brasileira protegida sob as diversas modalidades de unidades de conservação, apesar da precariedade da situação das UCs existentes que apresentam problemas relacionados a falta de regularização fundiária, fiscalização e estrutura de apoio, além de conflitos com a população local. Atualmente áreas protegidas no Brasil são estabelecidas por duas leis: Lei $n^{0} 12.651 / 2012$ que institui dentro do Novo Código Florestal as Áreas de Preservação Permanente (APP) e Reserva Legal (RL) e o Sistema Nacional de Unidades de Conservação (SNUC) fundado pela Lei no 9.985/2000 (BRASIL, 2000; MEDEIROS et al., 2004, DOUROJEANI, 2013). 
As Unidades de Conservação (UCs) estabelecidas pelo SNUC são divididas em dois grandes grupos: Proteção Integral e Uso Sustentável, os quais são definidos de acordo com a relevância da conservação, importância e representatividade dos seus ecossistemas, uso dos seus recursos naturais e o contexto da região escolhida (BRASIL, 2000; BENSUSAN, 2006). As unidades de proteção integral são criadas e estabelecidas para serem protegidas na íntegra, sem nenhuma alteração ou modificação feita pelo homem e estão separadas em cinco categorias: Parque Nacional, Reserva Biológica, Estação Ecológica, Monumento Natural e Refúgio de Vida Silvestre (BRASIL, 2000).

Contudo, mesmo detentor de umas das mais exigentes legislações ambientais do mundo, o Brasil ainda não tem mostrado eficiência nas questões relacionadas às suas áreas protegidas. Existe dificuldade em monitorar grandes áreas de proteção e faltam recursos financeiros, humanos e infraestrutura o que consequentemente afeta a efetividade da gestão. Estes fatores resultam na falta de resultados satisfatórios para a Ciência da Conservação no Brasil, principalmente no que diz respeito às espécies ameaçadas de extinção (LIMA et al., 2005). Para Lemos de Sá (2000), a efetividade de manejo das unidades de conservação em geral, está relacionada com sua capacidade de cumprir seus objetivos básicos relacionados a proteção de mananciais e espécies ameaçadas, além e incentivo a pesquisa científica. Segundo Cases (2012), a eficiência de gestão está diretamente relacionada ao planejamento a partir do Plano de Manejo, obrigatoriedade estabelecido pelo SNUC (BRASIL, 2000). O plano de manejo elaborado pelo órgão gestor (governo federal, estadual, municipal ou proprietário particular), é responsável por estabelecer condições adequadas de infraestrutura, pessoal, e regularização fundiária, que permitam de fato proteger a área). Bensusan (2006), afirma que avaliar o quanto do objetivo de conservação já foi atingido pelas unidades já existentes ajuda a definir o quanto falta, assim como, determina a coerência de proteção, como no caso dos 'parques de papel' que entram nas contagens oficiais de áreas protegidas, sem de fato existirem.

O Estado de Sergipe é o menor da Federação, e apresenta-se bastante devastado com cerca de $90 \%$ de sua área utilizada como pastagens e agricultura, restando apenas algumas manchas da floresta costeira, mata de restinga, mata ciliar, cerrados arbustivos e caatinga (SANTOS \& ANDRADE, 1992). No estado, em uma área estadual de 22.050,40 km², apenas $5.750 \mathrm{~km}^{2}$ são cobertos por ecossistemas de Mata Atlântica, compreendendo uma faixa litorânea de $40 \mathrm{~km}$ (litoral/interior), desde a foz do São Francisco até a região de Mangue Seco, na divisa com a Bahia. Atualmente a cobertura vegetal original restringe-se a manguezais, vegetação de restinga e remanescentes de floresta tropical úmida, apresentando várias associações, com praias e dunas, e vegetação herbácea (SANTOS \& ANDRADE, 1992).

A área de abrangência do bioma Caatinga ocupa a parte oeste do estado e está altamente fragmentada e distribuída em muitos fragmentos de diferentes tamanhos. Apesar da pequena área e da grande devastação por conta da forte ação antrópica, os remanescentes de Mata Atlântica e Caatinga do estado são extremamente importantes, pois ainda abrigam uma elevada 
biodiversidade e inúmeros endemismos (SANTOS \& ANDRADE, 1992; CI DO BRASIL et al. 2002; CI DO BRASIL. 2003; CASTELLETTI et al., 2004; LEAL et al., 2005; LANDIM, FONSECA, 2007).

Segundo Gomes et al. (2006) Sergipe possui um dos menores percentuais de áreas naturais protegidas de forma Integral no país. Este é um fator preocupante, pois os remanescentes florestais que restaram ao Estado compreendem os Biomas da Caatinga e Mata Atlântica e resguardam fisionomias ameaçadas que possuem um relevante papel para a proteção da biodiversidade (SILVA \& SOUZA, 2009). Neste contexto, O MMA, (2002) relata que a carência de um Sistema regional eficiente de áreas protegidas na Caatinga é um obstáculo que precisa ser visto com mais atenção pelos governantes, visto que nenhum outro bioma brasileiro possui tão poucas Unidades de Conservação. Apenas $1,4 \%$ do seu território encontra-se em áreas protegidas por Unidades de Conservação de proteção integral e em Sergipe, o número de Unidades de Conservação neste Bioma ainda é muito pequeno, com três Unidades de proteção integral sendo uma administrada pelo Governo Federal (ICMBIO), uma Estadual (SEMARH); e a terceira sob a responsabilidade da Prefeitura Municipal de Canindé de São Francisco (GOMES et al., 2006; SEMARH, 2011b, PORTELA, 2014).

A implantação de áreas protegidas em Sergipe é muito recente, e ainda não há resposta se essas áreas estão cumprindo com os seus objetivos de criação. Deste modo, o presente trabalho teve como objetivo geral, caracterizar as Unidades de Proteção Integral do Estado de Sergipe, e como objetivos específicos descrever a situação atual de cada uma, avaliando a efetividade de manejo.

\section{MATERIAL E MÉTODOS}

\section{Áreas de Estudo}

O trabalho foi realizado em cinco Unidades de Conservação de Proteção Integral do Estado de Sergipe (Tabela 1). O Monumento Natural do Rio São Francisco foi a única Unidade de Proteção Integral do Estado não inclusa na pesquisa, uma vez que sua extensão abrange não apenas o Estado de Sergipe, mas também a Bahia e Alagoas.

A Reserva Biológica Santa Isabel (REBIOSI) abrange áreas dos municípios de Pirambu e Pacatuba, situados no litoral norte do estado (Figura 1A). A região da REBIO compreende cerca de $45 \mathrm{~km}$ de praias, as quais estão associadas a dunas, vegetação de restinga, lagoas permanentes e temporárias, manguezais e estuários (ICMBIO, 2010; OLIVEIRA \& SOUZA, 2011; BRAGHINI \& VILAR, 2013). Destaca-se por ser área de desova de tartarugas marinhas, sendo considerado o maior sítio reprodutivo da espécie Lepidochelys olivacea (ICMBIO, 2010).

O Refúgio de Vida Silvestre Mata do Junco (RVSMJ) está localizado no município de Capela, na região leste-central do Estado (Figura 1C). O RVS é considerado o segundo maior remanescente de Mata Atlântica do Estado, dispondo de mananciais importantes dentro do 
Estado uma vez que abriga mais de 13 nascentes. Adicionalmente, abriga uma espécie de primata endêmica e ameaçada de extinção, o guigó-de-Sergipe (SEMARH, 2011a; KOBAYASHI et al., 1999).

Tabela 1: Unidades de Conservação de Proteção Integral do Estado de Sergipe abordadas no presente estudo.

\begin{tabular}{|c|c|c|c|c|c|c|c|}
\hline $\begin{array}{l}\text { Unidade de } \\
\text { Conservação }\end{array}$ & $\begin{array}{l}\text { Ano de } \\
\text { Criação }\end{array}$ & $\begin{array}{l}\text { Decreto } \\
\text { de } \\
\text { Criação }\end{array}$ & Jurisdição & Localização & $\begin{array}{l}\text { Área } \\
\text { (ha) }\end{array}$ & Bioma & Sede \\
\hline $\begin{array}{l}\text { Reserva } \\
\text { Biológica Santa } \\
\text { Isabel }\end{array}$ & 1988 & $n^{\circ} 96.999$ & Federal & $\begin{array}{c}10^{\circ} 43^{\prime} 56.97 " \mathrm{~S} \\
36^{\circ} 50^{\prime} 36.62^{\prime \prime}\end{array}$ & 2.766 & $\begin{array}{l}\text { Zona } \\
\text { Costeira }\end{array}$ & Pirambu \\
\hline $\begin{array}{l}\text { Parque Natural } \\
\text { Municipal Lagoa } \\
\text { do Frio }\end{array}$ & 2001 & $n^{\circ} 041$ & Municipal & $\begin{array}{l}09^{\circ} 38^{\prime} 32.49488^{\prime \prime} \mathrm{S} \\
37^{\circ} 55^{\prime} 08.11202^{\prime \prime} \mathrm{W}\end{array}$ & 278,99 & Caatinga & $\begin{array}{l}\text { Povoado } \\
\text { Curituba }\end{array}$ \\
\hline $\begin{array}{l}\text { Parque Nacional } \\
\text { Serra de } \\
\text { Itabaiana }\end{array}$ & 2005 & $\begin{array}{l}\text { portaria } \\
\mathrm{n}^{\circ} 84.017\end{array}$ & Federal & $10^{\circ} 40^{\prime} \mathrm{S} 37^{\circ} 25^{\prime} \mathrm{O}$ & 7.966 & $\begin{array}{l}\text { Mata } \\
\text { Atlântica e } \\
\text { Caatinga } \\
\end{array}$ & $\begin{array}{l}\text { Areia } \\
\text { Branca }\end{array}$ \\
\hline $\begin{array}{l}\text { Monumento } \\
\text { Natural Grota do } \\
\text { Angico }\end{array}$ & 2007 & $n^{\circ} 24.922$ & Estadual & $\begin{array}{l}09^{\circ} 39^{\prime} 23^{\prime \prime} \mathrm{S} \\
37^{\circ} 40 \text { '28'W }\end{array}$ & 2.138 & Caatinga & $\begin{array}{l}\text { Poço } \\
\text { Redondo }\end{array}$ \\
\hline $\begin{array}{l}\text { Refúgio de Vida } \\
\text { Silvestre Mata do } \\
\text { Junco }\end{array}$ & 2007 & $\mathrm{n}^{\circ} 24.944$ & Estadual & $\begin{array}{l}10^{\circ} 32^{\prime} 20^{\prime \prime} \mathrm{S} \\
37^{\circ} 03^{\prime} 20^{\prime \prime} \mathrm{W}\end{array}$ & 894,76 & $\begin{array}{l}\text { Mata } \\
\text { Atlântica }\end{array}$ & Jela \\
\hline
\end{tabular}

O Parque Nacional Serra de Itabaiana (PARNASI) foi inicialmente classificado como Estação Ecológica Serra de Itabaiana e posteriormente, em 2005, transformou-se primeiro Parque Nacional do Estado (Figura 1B). O parque possui sua área nos municípios de Areia Branca, Itabaiana, Laranjeiras, Itaporanga D'ajuda e Campo do Brito, localizados na região central do Estado, no agreste Sergipano. O PARNASI é constituído pelas serra comprida, cajueiro e de Itabaiana, abrigando um ecossistema único de altitude e transição entre dois Biomas: Mata Atlântica e Caatinga e tem um papel importante para o Estado, principalmente para as populações locais que o utilizam para lazer e recreação (SOBRAL et al., 2007).

O Monumento Natural Grota do Angico (MONAGA) abrange áreas dos municípios de Poço Redondo e Canindé de São Francisco, no Oeste do Estado, compreendendo uma região de Caatinga a beira do Rio São Francisco (Figura 1D). O MONAGA possui paisagens cênicas, grande riqueza da fauna e flora nativas, espécies endêmicas e ameaçadas de extinção. Outro indicador relevante é seu valor histórico, já que os dois municípios na qual está inserida estiveram diretamente envolvidos no Movimento do Cangaço, marcado pela morte de Virgulino Ferreira da Silva, o Lampião, sua esposa Maria Bonita, juntamente com seu bando no ano de 1938, mais precisamente no município de Poço Redondo (SEMARH, 2011b; SOUZA, 2013). O Parque Natural Municipal Lagoa do Frio está localizado no povoado Curituba, situado a aproximadamente $20 \mathrm{~km}$ da sede do município de Canindé de São Francisco (Figura 1E). O parque está totalmente inserido na região da Caatinga sergipana, é a menor Unidade de Proteção Integral do Estado e a única de jurisdição municipal (Canindé do São Francisco, 2001). 


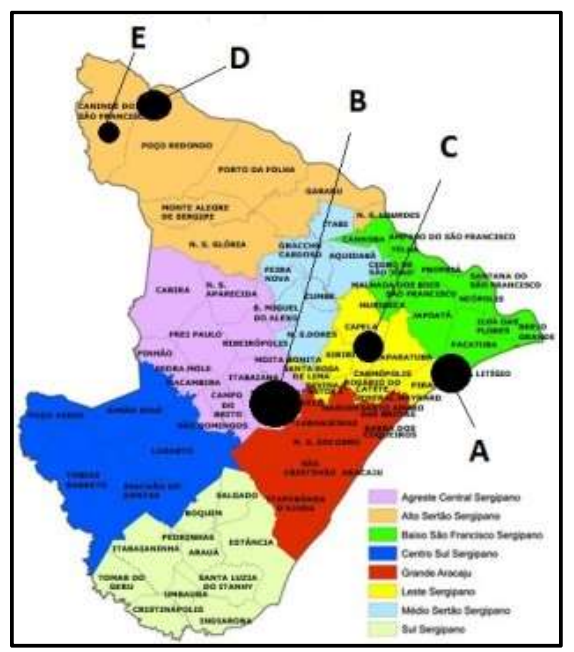

Figura 1: Distribuição espacial das Unidades de Conservação de Proteção Integral em Sergipe. A) REBIO Santa Isabel; B) PARNA Serra de Itabaiana; C) RVS Mata do Junco; D) MONA Grota do Angico; E) Parque Natural Municipal Lagoa do Frio.

\section{Coleta de Dados}

O trabalho foi realizado no período de Fevereiro a Junho de 2014. O projeto foi submetido, avaliado e aprovado pelo Comitê de Ética da Universidade Tiradentes (Aracaju, SE) sob o protocolo 27373014.2.0000.5371.

\section{Descrição e Caracterização das UCS}

A descrição das Unidades de Conservação de Proteção Integral foi feita por meio de revisão bibliográfica (artigos, dissertações, relatórios de pesquisa e mapas) e visita técnica. A visita técnica teve como objetivo caracterizar a situação de cada UC, sendo observada a infraestrutura, presença de funcionários e comunidades (Tabela 2). Adicionalmente, foram realizados registros fotográficos para ilustrar a pesquisa. Todas as visitas técnicas foram previamente autorizadas pelos órgãos gestores de cada unidade.

Tabela 2: Dados coletados in loco para caracterizar cada UC estudada.

\begin{tabular}{l|l|l}
\hline \multirow{4}{*}{ Infra estrutura } & Guarita & $\operatorname{Sim}($ ) Não ( ) \\
\cline { 2 - 3 } & Sede administrativa & $\operatorname{Sim}$ ( ) Não ( ) \\
\cline { 2 - 3 } & Alojamento & $\operatorname{Sim}($ ) Não ( ) \\
\cline { 2 - 3 } & Banheiros & $\operatorname{Sim}$ ( ) Não ( ) \\
\cline { 2 - 3 } & Laboratórios de Pesquisa & $\operatorname{Sim}$ ( ) Não ( ) \\
\cline { 2 - 3 } & Local para receber público (Auditório, anfi-teatro) & $\operatorname{Sim}$ ( ) Não ( ) \\
\hline \multirow{4}{*}{ Presença de Pessoas } & Funcionários & $\operatorname{Sim}($ ) Não ( ) \\
\cline { 2 - 3 } & Comunidades & $\operatorname{Sim}($ ) Não ( ) \\
\cline { 2 - 3 } & Visitantes & $\operatorname{Sim}($ ) Não ( ) \\
\hline
\end{tabular}

\section{Metodologia RAPPAM}

Para a avaliação da efetividade de gestão das Unidades de Conservação foi utilizada metodologia RAPPAM (Rapid Assessment and Prioritization of Protected Area Management) (IBAMAIWWF-Brasil 2007). A metodologia RAPPAM tem o intuito de confrontar em larga escala a 
situação em que se encontram várias Unidades de Conservação, não sendo interessante avaliar especificamente uma única UC. Tal metodologia compreende cinco passos: estabelecer o intuito de avaliação; avaliar as informações existentes sobre as unidades de conservação; aplicar o questionário; analisar os dados; e sugerir recomendações (WWF, 2003). O questionário original foi desenvolvido pela WWF (2003) e divide-se em três etapas: Perfil da UC; Pressões e ameaças e Real efetividade de manejo. Foram realizadas adaptações no questionário original devido a necessidade de adequação à realidade das áreas de estudo. O questionário foi aplicado individualmente para o gestor de cada uma das cinco unidades de conservação estudadas.

\section{Análise dos Dados}

Para cada pergunta do questionário havia quatro alternativas de respostas: Sim, Predominantemente Sim, Predominantemente Não e Não. Tais alternativas foram elaboradas com o objetivo de obter respostas mais amplas ao invés de alcançar respostas exatas sobre cada situação (WWF, 2003). No caso das "Pressões e Ameaças", a análise foi realizada diferente do questionário original, onde as quatro alternativas possuem significados distintos, assim sendo: resposta 'sim' indica que a pressão ou ameaça ocorre na região, resposta 'predominantemente sim' indica que a pressão ou ameaça ocorre na região esporadicamente, resposta 'predominantemente não' indica que a pressão ou ameaça ocorreu na região e não ocorre mais, 'não' indica que a pressão ou ameaça não ocorre na região. As respostas de cada questão do questionário foram pontuadas segundo WWF (2003) (Tabela 3). Para todos os parâmetros foram calculadas as frequências de resposta e gerado um gráfico comparativo entre as UCs. O Parque Natural Municipal Lagoa do Frio foi analisado separadamente das outras unidades por não possuir todos os dados e informações necessárias acessíveis para o preenchimento do questionário.

Tabela 3: Pontuação para cada categoria de resposta dentro do Método RAPPAM.

\begin{tabular}{ll}
\hline Resposta & Pontuação \\
\hline "Sim" (S) & 5 \\
"Predominantemente Sim" (P/S) & 3 \\
"Predominantemente Não" (P/N) & 1 \\
"Não" (N) & 0 \\
\hline
\end{tabular}

Fonte: WWF, 2007

\section{RESULTADOS}

Dentre as cinco Unidades de Conservação analisadas, apenas duas (RVSMJ \& MONAGA) possuem plano de manejo. Os planos de manejo destas unidades foram publicados três anos após sua criação e contaram com revisões, conferindo-lhes planos de manejo atuais, publicados em 2011. Estas unidades administradas pela gestão estadual obtiveram os melhores resultados em relação as UCs do âmbito federal. A eficácia de gestão das UCs estaduais deve-se em parte a existência dos planos de manejo, que embasam e fortalecem as ações de manejo dos gestores. 


\section{Descrição e Caracterização das UCS}

A REBIOSI é gerida pelo Instituto Chico Mendes de Conservação da Biodiversidade (ICMBIO) tendo como objetivo específico a conservação das tartarugas marinhas, destacando-se a Lepidochelys olivacea, espécie que mais desova nas praias da unidade. A UC possui dois servidores analistas ambientais do ICMBIO, e oito funcionários terceirizados. Há uma sede administrativa, não possui estrutura para desenvolver educação e sensibilização ambiental, nem laboratório para pesquisa e análise de dados. Uma sede do Programa Brasileiro de Conservação das Tartarugas Marinhas (TAMAR) esteve inserida dentro da unidade e desenvolveu pesquisas com as tartarugas marinhas e sensibilização ambiental para turistas e comunidades locais entre os anos de 1982 a 2014. Não há brigada de incêndio, nem guarita de segurança (SANTOS \& SANTOS, 2013).

Essa categoria de unidade de conservação não tem como objetivo o lazer e a recreação, dessa forma, a área da REBIO não possui trilhas abertas, nem placas de sensibilização. São encontradas apenas placas do Projeto TAMAR que visam informar as ameaças enfrentadas pelas tartarugas. O RVSMJ é gerido pela Secretaria de Estado do Meio Ambiente e dos Recursos Hídricos (SEMARH) e foi criado com objetivo principal de proteger a espécie Callicebus coimbrai ou macaco guigó, endêmica da região e ameaçada de extinção. Adicionalmente, a criação da UC protege a Mata Atlântica e seus recursos naturais, em especial as nascentes que estão dentro da UC como a do Riacho Lagartixo e permite a realização de pesquisas científicas, educação ambiental, ecoturismo e visitação pública (SEMARH, 2011a).

A UC dispõe de uma sede administrativa, guarita, estacionamento, alojamento, laboratório para realização de pesquisas científicas e Centro de Vivência onde são apresentadas aos visitantes a importância da unidade, seus objetivos e a ocorrência das espécies da fauna e flora local. Recentemente a unidade implantou placas interpretativas nas trilhas visando fortalecer a educação ambiental. A visitação é guiada pelos técnicos da unidade com auxílio de brigadistas e estagiários do órgão gestor. Atualmente o RVS conta com dois gestores, sendo um adjunto e mais dez servidores entre permanentes e terceirizados. Vinte voluntários integram a "Brigada de Prevenção e Combate a Incêndios Florestais", que auxiliam em ações educativas e combate a queimadas no entorno da unidade provenientes da queima de cana-de-açúcar. Placas e outdoors facilitam o acesso ao RVS, feito somente de transporte rodoviário (SEMARH, 2011a).

O PARNASI é administrado pelo ICMBIO e tem como objetivo específico a proteção dos Biomas Mata Atlântica e Caatinga. A UC possui cinco servidores e cinco funcionários advindos de terceirização, uma portaria e uma sede administrativa (Figura 4). Porém, não possui alojamento para pesquisadores nem laboratório de pesquisa, banheiros e infraestrutura para atender os visitantes e desenvolver trabalho de educação ambiental. É a maior unidade do Estado e considerada a principal, uma vez que apresenta fitofisionomias de dois grandes Biomas 
brasileiros, a Mata Atlântica e a Caatinga, além de ser referência para prática do ecoturismo, e servir de lazer e recreação para a população, principalmente dos municípios de Itabaiana e Areia Branca (OLIVEIRA et al., 2009).

O MONAGA é gerido pela Secretaria de Estado do Meio Ambiente e dos Recursos Hídricos (SEMARH) e sua criação teve como objetivos específicos preservar o sítio natural da Grota do Angico e elementos culturais associados, mantendo a integridade dos ecossistemas naturais da Caatinga, promovendo o desenvolvimento de pesquisa científica, educação ambiental, ecoturismo e visitação pública (SEMARH, 2011b). A UC dispõe de sede administrativa, mirante, um laboratório, alojamento e um Centro de Vivência onde existe uma exposição de fotos da diversidade biológica da unidade e seus valores históricos. Atualmente o MONAGA conta com dois gestores, sendo um adjunto e mais nove servidores entre permanentes e terceirizados. $A$ visitação a trilha da Grota do Angico é guiada pelos técnicos e servidores. A unidade ainda não dispõe de placas interpretativas na trilha, porém o projeto de "Sinalização de Trilhas Interpretativas" encontra-se em andamento.

\section{Metodologia RAPPAM}

A pontuação total dos parâmetros avaliados variou entre 15 e 80 pontos e cada UC estudada teve sua pontuação somada por parâmetro (Tabela 4).

Tabela 4: Pontuação Total para cada categoria dentro do método Rappam e Pontuação de Respostas para os parâmetros Pressões e Ameaças e Efetividade de Gestão das Unidades de Conservação de Proteção Integral do Estado de Sergipe. PARNASI = Parque Nacional Serra de Itabaiana; REBIOSI = Reserva Biológica Santa Isabel; RVSMJ = Refúgio de Vida Silvestre Mata do Junco; MONAGA = Monumento Natural Grota do Angico.

\begin{tabular}{|c|c|c|c|c|c|}
\hline & $\begin{array}{l}\text { PONTUAÇÃO } \\
\text { TOTAL }\end{array}$ & PARNASI & REBIOSI & RVSMJ & MONAGA \\
\hline A. Pressões e Ameaças & 80 & 22 & 60 & 43 & 29 \\
\hline \multicolumn{6}{|l|}{ B. Efetividade de Gestão } \\
\hline B1. Importância Biológica & 40 & 25 & 36 & 38 & 32 \\
\hline B2. Importância Socioeconômica & 40 & 40 & 35 & 25 & 30 \\
\hline B3. Vulnerabilidade & 25 & 10 & 19 & 3 & 12 \\
\hline B4. Objetivos & 20 & 13 & 13 & 20 & 16 \\
\hline B5. Amparo Legal & 15 & 0 & 3 & 13 & 13 \\
\hline B6. Desenho e Planejamento da área & 20 & 10 & 11 & 15 & 15 \\
\hline B7. Recursos Humanos & 20 & 13 & 6 & 16 & 12 \\
\hline B8. Comunicação e Informação & 25 & 20 & 11 & 25 & 25 \\
\hline B9. Infraestrutura & 20 & 3 & 12 & 16 & 18 \\
\hline B10. Recursos Financeiros & 20 & 5 & 15 & 13 & 16 \\
\hline B11. Planejamento da Gestão & 20 & 0 & 6 & 16 & 14 \\
\hline B12. Processo de Tomada de Decisão & 25 & 15 & 16 & 25 & 25 \\
\hline B13. Pesquisa, Avaliação e Monitoramento & 20 & 16 & 5 & 18 & 12 \\
\hline B14. Resultados & 55 & 30 & 37 & 53 & 49 \\
\hline B15. Políticas de Unidades de Conservação & 45 & 8 & 20 & 26 & 35 \\
\hline B16. Contexto Político & 25 & 15 & 15 & 23 & 25 \\
\hline
\end{tabular}

As pressões e ameaças apresentaram a maior frequência para REBIOSI enquanto o PARNASI obteve a menor frequência (Gráfico 1). Dentre as 16 pressões e ameaças apresentadas 
no questionário, apenas duas, incêndios de origem antrópica e mineração, não ocorrem na REBIOSI.

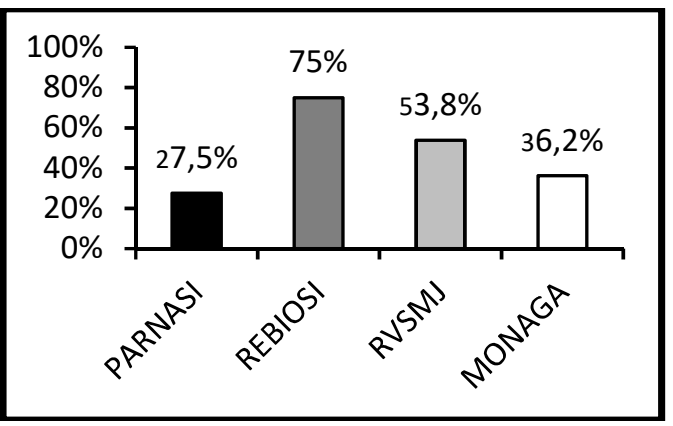

Figura 6: Frequência de resposta para o parâmetro Pressões e Ameaças das Unidades de Conservação de Proteção Integral do Estado de Sergipe. PARNASI = Parque Nacional Serra de Itabaiana; REBIOSI = Reserva Biológica Santa Isabel; RVSMJ = Refúgio de Vida Silvestre Mata do Junco; MONAGA = Monumento Natural Grota do Angico.

Todas as UCs estudadas apresentaram altos valores para importância biológica. O RVSMJ e a REBIOSI apresentaram valores acima da média e o PARNASI obteve a menor frequência neste parâmetro (Figura 7). O valor socioeconômico também foi alto para todas as UCs estudadas. O PARNASI obteve a maior frequência neste parâmetro, seguida da REBIOSI, e ambas apresentaram frequência acima da média. Para a vulnerabilidade, a variação entre as UCs foi grande onde a REBIOSI apresentou a maior frequência, seguida de MONAGA e PARNASI e o RVSMJ apresentou frequência baixa (Figura 7).

Com relação aos objetivos da UC, todas as UCs estudadas mostraram valores acima de $60 \%$. No parâmetro Amparo Legal, as diferenças foram grandes entre as UCs. O PARNASI não obteve nenhuma pontuação indicando uma situação extremamente crítica no que tange a proteção da unidade. O RVSMJ e o MONAGA apresentaram frequências iguais. As frequências para desenho e planejamento da área variaram entre 50 e $75 \%$ como valores iguais para RVSMJ e MONAGA. Os recursos humanos se mostraram baixos somente para a REBIOSI (Figura 7).

A comunicação e informação foram menores dentro da REBIOSI e apresentaram frequências maiores que $80 \%$ para as outras UCs estudadas. As unidades estaduais apresentaram frequências acima da média para a infraestutura. O PARNASI obteve frequência abaixo da média mostrando a falta de recursos financeiros. Já a REBIOSI e o MONAGA mostraram possuir recursos financeiros. Para planejamento da gestão, a frequência das UCs estaduais ficou acima da média, diferentemente do PARNASI e a REBIOSI (Figura 7).

O RVSMJ e o MONAGA mostraram um resultado satisfatório para o parâmetro processo de tomada de decisão, enquanto PARNASI e REBIOSI apresentaram valores acima de 60\%. Com relação a pesquisa, avaliação e monitoramento, a menor frequência foi encontrada para a REBIOSI e as outras UCs apresentaram valores altos para este parâmetro. Apenas as unidades estaduais apresentaram frequência acima da média, demonstrando possuir um ótimo quadro de resultados. Já as Unidades Federais não ultrapassaram a média. Apenas as UCs estaduais se mantiveram acima da média para o parâmetro políticas de unidades de conservação. Finalmente 
para o contexto político, as unidades estaduais apresentaram frequência acima da média e as federais abaixo, isso se deve a falta de compromissos e recursos financeiros para as UCs federais (Gráfico 2).

A alta taxa de pressões e ameaças dentro da REBIOSI mostra que a UC pode estar sendo altamente impactada. O questionário mostrou que a pesca ocorre com frequência na REBIO o que corrobora com dados do ICMBIO (2010) que afirmam a ocorrência da pesca com rede de arrasto no entorno da unidade assim como pastagens de gado na restinga e plantação de espécies exóticas, como o coco (Coco nucifera). O turismo e a recreação são mantidos como alerta na REBIOSI e vale ressaltar que essa atividade vai contra os objetivos estabelecidos pelo SNUC para essa categoria de UC. Neste contexto, Oliveira; Gomes; Santos (2009) alertam que os visitantes colaboram para o aumento dos impactos negativos, já que a maioria dos frequentadores das comunidades do entorno não são sensíveis às questões ambientais.

Para o PARNASI, a disposição de resíduos não foi considerada uma ameaça, pois todo o resíduo gerado é coletado pelos funcionários do órgão responsável. O turismo e recreação também não foram vistos como uma ameaça. A pastagem é de ocorrência apenas para o entorno da UC, e não foi considerada ameaça, já que ocorre em pequena escala, como forma de subsistência para as pequenas propriedades. Apesar das respostas geradas pelo questionário mostrarem que a situação do PARNASI é adequada, durante a observação in loco constatou-se que a presença de pessoas pode ser uma ameaça, visto que ocorre a disposição de resíduos, poluição sonora e pisoteio das trilhas, o que causa uma série de impactos aos recursos naturais da unidade. Além disso, Sobral et al. (2007) aponta que o PARNASI é única unidade em que ocorre conversão do solo e mineração no seu entorno, principalmente com retirada de areia e argila. O questionário mostrou que a maioria das pressões e ameaças como disposição de resíduos, extração de madeira, pastagens, já foram registradas no MONAGA, porém não ocorrem atualmente. Entretando, a coleta de produtos não madeireiros é uma ameaça a biodiversidade do RVSMJ e MONAGA, como por exemplo a coleta do cabeça-de-frade (Melocactus bahiensis) usado pelas populações locais (SEMARH, 2011b). As categorias MONA e RVS permitem propriedades particulares em seu interior, desde que estejam de acordo com os objetivos de sua gestão (BRASIL, 2000).

A caça foi uma atividade registrada para todas as unidades, tanto no seu interior, como no entorno. A caça de animais silvestres é uma prática ainda muito difundida em todo o país, principalmente no semiárido brasileiro, onde está relacionada aos valores culturais e socioeconômicos muito importantes para região, satisfazendo diversas finalidades, dentre elas alimentação, lazer e ornamentação (ALVES, 2012). Rinaldi (2005) confirmou essa mesma atividade em seis unidades de conservação do município do Rio de Janeiro. 


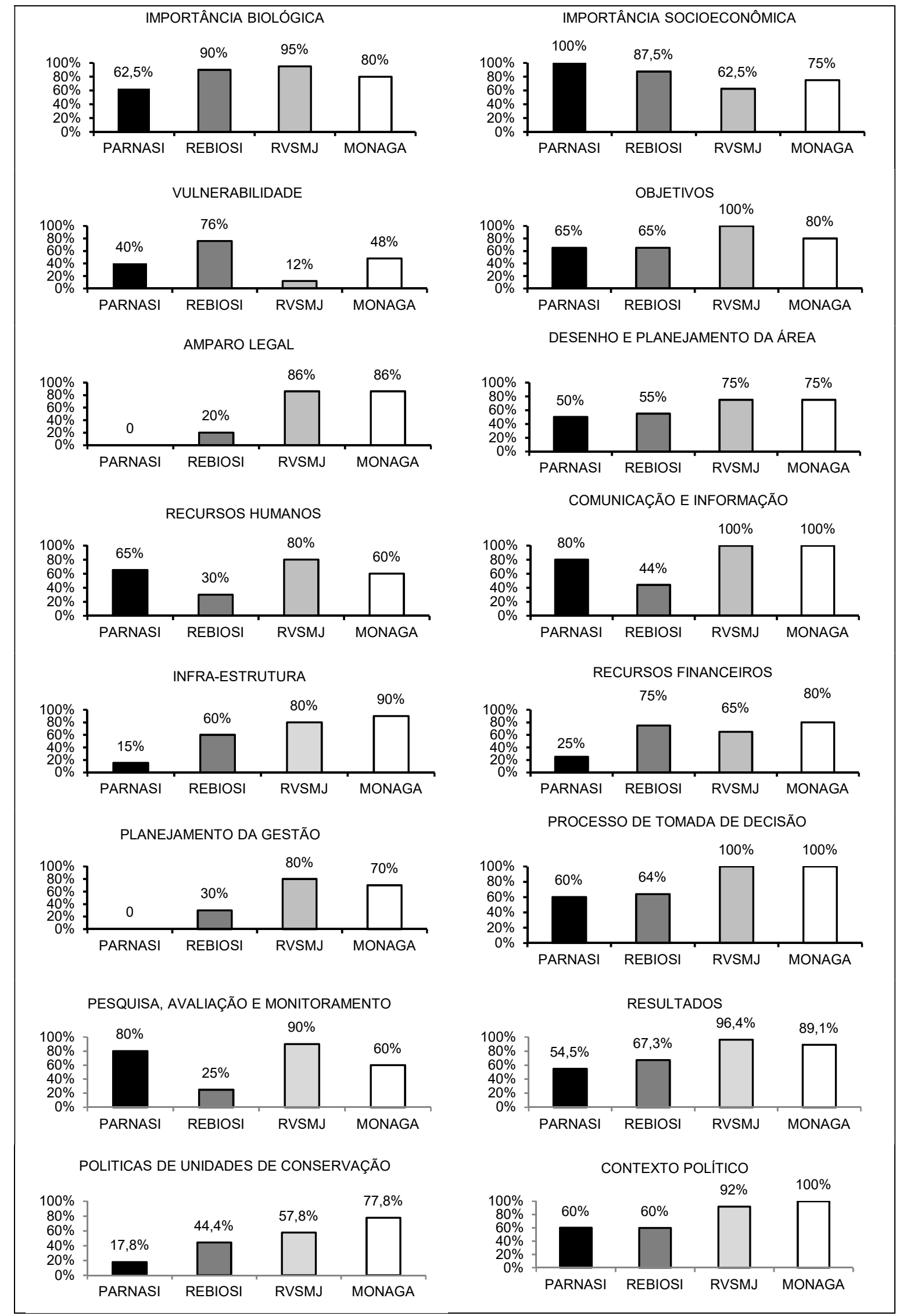

Gráfico 2: Frequências de respostas para os parâmetros de Efetividade de Gestão das Unidades de Conservação de Proteção Integral do Estado de Sergipe. PARNASI = Parque Nacional Serra de Itabaiana; REBIOSI = Reserva Biológica Santa Isabel; RVSMJ = Refúgio de Vida Silvestre Mata do Junco; MONAGA = Monumento Natural Grota do Angico. 
Os altos valores para importância biológica em todas as UCs indicam um alto nível de biodiversidade e processos naturais, além de terem importante representação no Sistema de Áreas Protegidas do Estado. As maiores frequências para RVSMJ e REBIOSI devem-se ao fato dessas unidades abrigarem espécies ameaçadas de extinção como o macaco-guigó e as tartarugas marinhas respectivamente, que são alvos de pesquisas e importantes para a conservação. A importância biológica indicada para o MONAGA corrobora com Aguilar (2014), que encontrou um total de 129 espécies entre endêmicas, ameaçadas e indicadoras de hábitat apenas para o grupo de aves. Silva et al. (2013) identificou no MONAGA uma espécie vegetal considerada rara Lippia pedunculosa. O PARNASI obteve a menor frequência neste parâmetro e segundo dados do questionário, a UC não apresenta níveis significativos de endemismo e nem populações mínimas viáveis de espécies chaves. Em contrapartida, Sobral et al. (2007) afirma que o PARNASI é essencial para a proteção da fauna e flora, pois abriga espécies endêmicas como Herpsilochmus pectoralis e Nothroctenus fuxic. O ICMBio (2011) também destaca a presença de cinco espécies da fauna ameaçadas de extinção dentro do PARNASI afirmando a expressividade da diversidade biológica dentro da UC.

A alta importância socioeconômica atribuída ao PARNASI provavelmente deve-se ao seu grande potencial turístico, sendo as visitações bastante frequentes para prática de esportes radicais e lazer. Rinaldi (2005) avaliando a efetividade de manejo de seis unidades de conservação da cidade do RJ concluiu que apenas o Parque Nacional da Tijuca possuía nível satisfatório de manejo. Esse resultado deve-se em parte a intensa visitação e a fama da unidade. Ainda dentro deste parâmetro, foi avaliada a importância religiosa ou espiritual das UCs e tanto o RVSMJ quanto a REBIOSI não apresentaram essa característica por parte das populações locais. Sob outra perspectiva, o PARNASI e o MONAGA apresentam importância religiosa e espiritual para as populações locais. Segundo o IBAMA (2006) já foram constatados incêndios gerados por atividade desta natureza no PARNASI. Da mesma maneira, a realização da 'Missa do Cangaço', ocorre anualmente no MONAGA em virtude da comemoração da morte do cangaceiro Lampião.

A REBIOSI apresentou maiores riscos á sua integridade devido a alta vulnerabilidade, com registro de atividades ilegais e muitos acessos para a prática das mesmas. De acordo com o SNUC (2000), a categoria Reserva Biológica não permite que populações façam qualquer tipo de uso direto dos recursos naturais, admitindo apenas a execução de atividades educacionais. questionário registrou uma quantidade insuficiente de recursos humanos devido a contratação e manutenção de funcionários ser considerada difícil. Isso provavelmente favorece a prática das atividades ilegais tornando a biodiversidade da REBIOSI totalmente vulnerável. Todas as UCs apresentaram variados acessos na sua área para a prática de atividades ilegais, sendo a caça e o extrativismo as mais citadas. O RVSMJ apresentou menor frequência de vulnerabilidade, indicando inexistência de conflitos com a população do entorno, porém a 'Festa do Mastro', que ocorre anualmente no município, é um indicativo de ameaça mesmo com o acordo existente entre a população e o órgão gestor em relação a escolha da árvore retirada do interior da UC 
(SEMARH, 2011a). Dados do questionário indicam que a população do entorno do MONAGA contribuem com medidas de proteção, pois as mesmas comunicam ocorrências de desmatamento ilegal e exigem fiscalização.

Para os parâmetros objetivos, as UCs RVSMJ e MONAGA mostraram maiores frequências, pois estas unidades são as únicas que apresentam plano de manejo onde constam os objetivos específicos de manejo. A existência do plano de manejo é a base das atividades de proteção para qualquer categoria de área protegida (FARIAM et al., 2007). O apoio da comunidade que vive no entorna das UCs estaduais é significativo e deve-se ao fato das mesmas participarem dos conselhos consultivos (SEMARH, 2011a; SEMARH, 2011b). BRASIL (2000) estabelece um prazo máximo de cinco anos após a criação da UC para a elaboração do plano de manejo, porém as REBIOSI e o PARNASI ultrapassaram esse prazo e ainda não possuem seus planos de manejo publicados. Segundo o questionário o plano de manejo do PARNASI encontrase em fase de elaboração e o da REBIOSI está concluído, porém ainda não foi publicado.

Com relação ao amparo legal, verificou-se que a situação fundiária do PARNASI não está regularizada, pois os limites da unidade não são claramente demarcados e não existe implementação da lei por falta de recursos humanos e financeiros, fato que corrobora com o estudo do IBAMA (2006). Oliveira et al. (2009) identificaram degradações alarmantes nas trilhas de visitação do PARNASI, pondo em risco para visitantes e fauna adjacente. Neste mesmo estudo, as autoras mostraram que $95,1 \%$ da área do PARNASI é ocupada por atividades agrícolas. A situação fundiária da REBIOSI encontra-se parcialmente regularizada, restando apenas uma propriedade. Para o RVSMJ e o MONAGA, a regularização fundiária foi obtida nos estudos prévios para a implementação das mesmas. Foi apontada nestas unidades a necessidade de um número maior de recursos humanos como guardas-parques e maiores investimentos financeiros para efetiva aplicação da lei. Rocha et al. (2010) analisando dados do ICMBIO referentes à regularização fundiária em parques nacionais concluíram que nenhuma UC estudada foi classificada como 'totalmente regularizada' pelo próprio órgão.

O desenho e planejamento das UCs estudadas mostram que as terras no entorno de todas são utilizadas pela população local, conferindo fortes ameaças a integridade das unidades ao longo dos anos. O sistema de zoneamento do RVSMJ e do MONAGA está bem definido segundo informações e mapas presentes nos seus planos de manejo. Não houve processo participativo significante na definição da categoria da REBIOSI e isso talvez explique o fato da categoria estabelecida para a unidade não esteja adequada para as ações de manejo. Nenhuma das unidades estudadas está ligada a outras áreas protegidas.

No parâmetro Recursos humanos, o RVSMJ apresentou a maior frequência, mas apontou a necessidade de aumento no número de funcionários dentro da unidade devido a sobrecarga de atividades para se ter uma fiscalização mais eficaz nas áreas de difícil acesso. A REBIOSI obteve a menor frequência apresentando condições de trabalho insuficientes para manter equipe de alta qualidade. Rinaldi (2005) observou o mesmo para as UCs do município do Rio de Janeiro, 
concluindo que existe um número insuficiente de funcionários atuando nas unidades e estes são mal distribuídos. Kornijezuk (2012) identificou apenas três servidores públicos atuando na gestão de um PARNA no Amapá o que limitou a realização de outros estudos na área do parque. Em contraste, no mesmo estudo, a autora identificou uma grande equipe de trabalho composta por cem pessoas, das quais quarenta foram contratadas através de concurso público, atuando na gestão de um PARNA criado na França.

Os recursos humanos necessários para atuar nas UCs federais estão defasados, com um saldo negativo de 7.000 servidores, o que leva a uma limitação nesse setor e não dá garantia na efetividade da conservação da biodiversidade brasileira (SILVA, 2012). É nítido que atualmente o ICMBIO apresenta um déficit de recursos humanos, uma vez que as vagas são ofertadas apenas mediante concurso público e os concursos demoram para serem realizados e a maioria das vagas ofertadas são destinadas a outros Estados.

Uma informação importante registrada no questionário foi a confirmação por parte de todas as UCs quanto a comunicação entre si, o que é significante para troca de experiências e informações, em todas as esferas de gestão. No PARNASI e na REBIOSI foi constatado que não há sistema adequado para armazenar, processar e analisar dados. As unidades estaduais apresentaram frequências acima da média para a infraestutura, pois todas as UCs possuem infraestrutura adequada para realizar ações de manejo. Contudo, o RVSMJ e MONAGA, apresentam dificuldades pelo fato de compreender áreas de difícil acesso e não possuir veículos de tração. Três UCs possuem equipamentos de campo e instalações razoavelmente adequadas para realizar ações de manejo e receber visitantes, exceto o PARNASI.

As fontes financeiras e captação de recursos variam entre as UCs estudadas. O PARNASI não possui recursos financeiros adequados para atingir as ações de manejo, não tem nenhuma outra fonte financeira além daquelas oriundas do órgão responsável e não há previsão dos mesmos para os próximos anos. O RVSMJ também não possui outras fontes financeiras além daquelas provenientes do órgão responsável. Flores et al. (2009) estudando duas unidades de conservação do litoral do RS, encontraram a mesma dificuldade na captação de recursos financeiros para as UCs. No caso do PARNASI, por ser uma unidade apropriada para visitação pública e turismo, uma sugestão seria a cobrança de taxa de entrada como uma segunda fonte de renda, além de limitar a visitação, o acesso e consequente devastação local. Em contrapartida, a REBIOSI e o MONAGA, possuem recursos financeiros advindos de compensação ambiental. A compensação ambiental é um mecanismo presente na Lei 9.985/2000, que deve ser bastante debatido para que seja aprimorado, mas que já vem funcionando como importante ajuda para diversas UCs que se encontram em estados precários devido à falta de prioridade política e financeira, além de contribuir para a criação de novas unidades de proteção integral, que são as grandes responsáveis pela preservação da natureza (GELUDA, 2004). 
O planejamento da gestão mostrou-se efetivo para as UCs estaduais, pois as mesmas têm planos de manejo atuais, os quais possuem inventários da biodiversidade. Porém, verifica-se pouca abrangência para alguns grupos como constatado por Souza; Ferreira; Coelho (2014) que em sua análise dos levantamentos biológicos dos planos de manejo dessas UCs, verificaram não haver levantamento para invertebrados, fungos e vegetais inferiores. Diferentemente, o PARNASI e a REBIOSI não possuem inventários, dificultando desta forma, o conhecimento dos recursos naturais e culturais das mesmas.

O RVSMJ e o MONAGA mostraram um resultado satisfatório para o processo de tomada de decisão, pois possuem conselhos consultivos, comunicação transparente entre funcionários e gestores e uma organização nítida de pessoal. No questionário, foi registrado que estas UCs também têm participação das comunidades locais na tomada de decisões. Entretanto, Almeida et al. (2014) constataram que $70 \%$ dos moradores do entorno do MONAGA não tem conhecimento da existência da unidade, desta forma, talvez exista falta de comunicação entre o Conselho consultivo e parte da população. Concomitantemente, Melo; Andrade; Santana (2013) registraram que moradores do entorno da REBIOSI não tiveram nenhuma participação na criação da unidade e relataram conflitos com o uso dos recursos. Silva e Souza $(2010 ; 2013)$ analisando os conflitos territoriais gerados nas APAS Sergipanas apontaram a necessidade de envolvimento da diversidade sociocultural na gestão dessas unidades, para que ao menos, minimize a oposição de interesses. Independente da categoria é fundamental que comunidades ligadas a futuras áreas protegidas sejam informadas pelos órgãos gestores e pela ciência sobre todas as etapas de criação e estejam envolvidas no processo (Instituto Socioambiental, 2013).

A pesquisa, avaliação e monitoramento apresentaram menor frequência para a REBIOSI, onde os impactos das atividades legais e ilegais não são monitorados de forma precisa. Apenas o PARNASI não possui as necessidades críticas de pesquisa e monitoramento, identificadas e priorizadas, mesmo assim, igualmente ao RVSMJ, obtiveram as maiores frequências para este parâmetro. Apenas as unidades estaduais apresentaram frequência acima da média, demonstrando possuir um ótimo quadro de resultados. Já as Unidades Federais não ultrapassaram a média, mas possuem conselhos que organizam capacitação e desenvolvimento das comunidades locais.

A REBIOSI não realiza implantação e manutenção da infraestrutura, já que o ICMBIO não viabiliza verbas para tal. Também não é realizado controle de visitantes e turistas, já que a presença desses não corrobora com os objetivos do tipo de UC. Um cenário semelhante foi encontrado no Parque Natural Municipal Tupancy, no litoral norte gaúcho por Flores et al. (2009) onde os autores destacam a importância do registro turístico para que ocorram ações de educação ambiental mais eficazes. O PARNASI não possui trabalhos de recuperação das áreas e ações mitigatórias, manejo da vida silvestre ou do habitat e recursos naturais, e nem monitora seus resultados. 
Um indicador relevante é a presença em todas as unidades de pesquisas científicas, e segundo Battesini et al. (2013) os convênios estabelecidos entre universidades e os governos federal e estadual concebem um significativo avanço nas pesquisas relacionadas a unidades de conservação. Ambas as UCs federais não possuem metas para recuperar seus ecossistemas reduzidos, pesquisas contínuas sobre questões críticas, e inventário sobre sua biodiversidade o que resultou em valores baixos para as políticas de unidades de conservação. Entretanto, mesmo sem a publicação do plano de manejo, foram encontrados trabalhos de levantamento da Biota, tanto para o PARNASI (IBAMA, 2005), quanto para REBIOSI (ICMBIO, 2010). Por outro lado, com relação ao contexto político, as unidades estaduais apresentaram frequência acima da média e as federais abaixo, isso se deve a falta de compromissos e recursos financeiros para as UCs federais. A efetividade de manejo em duas APAS do litoral baiano, concluíram que o manejo considerado regular na APA Costa de Itacaré/Serra Grande foi conquistado devido ao intenso envolvimento de órgãos governamentais e da sociedade civil.

\section{O Caso do Parque Natural Municipal Lagoa do Frio}

No Município de Canindé de São Francisco, região da Caatinga sergipana, encontram-se três Unidades de Conservação de proteção integral: O Monumento Natural do Rio São Francisco, administrado pelo Governo Federal (ICMBIO), o qual abrange além do Estado de Sergipe, a Bahia e Alagoas; o Monumento Natural Grota do Angico, de administração Estadual (SEMARH); e o Parque Natural Municipal Lagoa do Frio, sob a responsabilidade da Prefeitura Municipal de Canindé de São Francisco (GOMES et al., 2006; SEMARH, 2011b).

O Parque Natural Municipal Lagoa do Frio, situado no povoado Curituba é a única Unidade de Conservação de Proteção Integral no âmbito municipal dentro do Estado de Sergipe. Sua área foi desmembrada da Fazenda Velha, de posse e domínio público do município de Canindé do São Francisco. A UC é administrada pelo Departamento de Meio Ambiente da Secretaria Municipal de Agricultura e Meio Ambiente e o objetivo de sua criação foi preservar o ecossistema natural da Caatinga de grande relevância sócio-ambiental, assegurando a realização de pesquisas científicas, o desenvolvimento de atividades de educação e interpretação ambiental, de recreação em contato com a natureza e de turismo ecológico, como também contribuindo para a preservação e valorização da diversidade cultural existente na região (CANINDÉ DO SÃO FRANCISCO, 2001).

A UC não possui um gestor oficial e funcionários, assim como não há construída nenhuma infraestrutura. Existem três documentos relacionados a UC, mas somente seu decreto é oficial. Ao visitar o local foi verificado que a área é utilizada para abrigar animais que são apreendidos pela Prefeitura e não existem pesquisas científicas referentes a UC. As populações do entorno não conhecem a área como uma unidade de conservação e sim como "Parque de Vaquejada", onde uma vez por semana ocorre essa atividade. Diante dessa situação, a prefeitura não obteve 
sucesso na sua proteção e esse conflito resultou na desistência da mesma em privar a atividade dentro da UC. Hoje a chave está sob responsabilidade dos vaqueiros que continuam utilizando o espaço semanalmente. É comum em diversos municípios do interior do Brasil, principalmente nas fazendas de criação de gado, a ocorrência dessas atividades lúdicas e/ou esportivas em que se monta em touros ou cavalos. A vaquejada é caracterizada pela soltura de bovinos e equinos, para a disputa pela captura dos mesmos, onde o animal é derrubado utilizando o laço (DOURADO, 2013).

A realidade a qual se encontra o Parque não é condizente com o objetivo desta categoria, que segundo SNUC, é preservar ecossistemas naturais de grande relevância ecológica e beleza cênica, possibilitando a realização de pesquisas científicas e o desenvolvimento de atividades de educação ambiental, de recreação em contato com a natureza e turismo ecológico (BRASIL, 2000). O SNUC é regido por diretrizes, dentre elas afirma-se que a participação efetiva das populações locais na criação, implantação e gestão das unidades de conservação deve ser assegurada (BRASIL, 2000). Bensusan (2006) reforça que para a gestão efetiva de uma UC, é de extrema importância a conciliação da população local com o órgão gestor, havendo uma gestão participativa, o que não ocorre no presente caso onde é evidente a presença de conflitos entre a população e órgão gestor. Oliveira (2013) destaca em seu trabalho realizado no Parque Nacional Grande Sertão Veredas a preocupação do governo, nesse caso na esfera federal, em preservar a biodiversidade, porém, sem levar em conta a cultura e o conhecimento tradicional da população ali presente, o que pode gerar possíveis embates, assim como ocorre Parque Natural Municipal Lagoa do Frio.

Possivelmente não existe interesse na preservação e conservação do ambiente em questão, pois no local são soltos animais, sem nenhum estudo prévio. A utilização da área para a vaquejada também mostra a falta de imposição e fiscalização do órgão responsável. A criação de uma UC, apesar de minimizar uma problemática ambiental pode estar atrelada a conflitos que provocam impactos diretos ou indiretos e como consequências surgem características negativas ao ambiente natural como degradação e desequilíbrio; ameaças à sustentabilidade, aos bens coletivos e recursos naturais; além da perda de biodiversidade (RIBEIRO, 1995; HERCULANO, 2006).

O Parque Natural Municipal Lagoa do Frio pode ser considerado um 'Parque de Papel', que segundo Terborgh eSchaik (2002) é apenas uma área cercada, onde não há nenhuma perspectiva ou diretrizes para o seu manejo efetivo. São também chamados de 'Unidades no papel', criadas pelo poder público, mas sem continuidade dos investimentos necessários à sua consolidação (SALMONA, 2014). Essas áreas dificilmente são implementadas na prática e muito menos atendem aos anseios das políticas de conservação da biodiversidade (SILVA, 2012). Segundo diversos autores, a criação e implementação de UCs geralmente implica em conflitos políticos, econômicos, culturais, sociais e ambientais envolvendo várias dimensões, atores e interesses (SILVA \& SOUZA, 2010; SILVA, 2012). Inúmeras UCs são estabelecidas em gabinetes 
oficiais, onde geralmente não houve conhecimento prévio da área selecionada, e isso acaba gerando uma série de conflitos que estão longe de serem minimizados (SILVA, 2002).

Em contrapartida, Dourojeanni (2013) afirma que o simples ato do estabelecimento legal da Unidade de Conservação, torna os Parques de Papel protegidos em boa parte de sua integridade natural em virtude de serem terras públicas. Salmona (2014) também defende que os Parques de papel conservam, mas ressalta a necessidade de maiores investimentos para cumprirem plenamente seus objetivos. Silva (2012) ressalta que a criação de unidades de conservação serve para delimitar o território, sendo uma estratégia para assegurar o controle ou limitação de acesso e uso das áreas.

Apesar do Parque Natural Municipal Lagoa do frio estar dentro das estatísticas de UCs de proteção integral do Estado de Sergipe esta unidade não deveria estar nesta lista já que é apenas uma área cercada sem nenhuma perspectiva de manejo e provavelmente foi criada como estratégia política. Uma estratégia seria a busca de alternativas para reverter esse cenário, como parcerias entre o seu órgão gestor e outras instituições e organizações, propor a mudança de categoria ou ainda a extinção da unidade.

\section{CONCLUSÕES}

O Parque Nacional Serra de Itabaiana obteve resultados críticos de manejo e apesar de ser a maior e principal unidade de proteção integral do Estado, não possui seu principal instrumento de gestão, o plano de manejo, além de infraestrutura adequada para receber visitantes e pesquisadores. Assim como o PARNASI, a Reserva Biológica Santa Isabel obteve resultados críticos, principalmente por ser a unidade de conservação mais antiga do Estado, e também não possuir o Plano de Manejo. A falta de recursos humanos e vulnerabilidade foram comprovadas para a UC, o que mostra a carência de funcionários e a necessidade de concursos com vagas destinadas para a unidade. Outro ponto que vale ressaltar, é que a unidade está inserida em uma categoria inadequada do SNUC. O Refúgio de Vida Silvestre Mata do Junco e o Monumento Natural Grota do Angico obtiveram os melhores resultados quanto à efetividade de manejo, uma vez que possuem planos de manejo estabelecidos no prazo determinado, um maior número de funcionários e a infraestrutura consegue atender as suas necessidades na medida do possível. Todavia, essas unidades ainda não atingiram um padrão de excelência. Constatou-se que o Parque Natural Municipal Lagoa do Frio é um "parque de papel" e provavelmente foi criado como estratégia política. Sendo assim, não deveria estar na lista de unidades de conservação de Proteção Integral do Estado de Sergipe, já que é apenas uma área cercada sem nenhuma perspectiva de manejo. Com isso, o Bioma Caatinga é protegido apenas pelo Monumento Natural Grota do Angico. A melhor estratégia para o Parque Natural Municipal Lagoa do Frio seria a sua extinção, ou a busca do seu órgão gestor por alternativas para melhorar o cenário atual da UC. 


\section{REFERÊNCIAS}

AGUILAR; J. M. R. E.. Sustentabilidade das Comunidades de Aves em Duas Áreas Protegidas do Estado de Sergipe. Tese (Doutorado em Desenvolvimento e Meio Ambiente) - Universidade Federal de Sergipe, São Cristóvão, 2014.

ALMEIDA, C. P.; SAMPAIO, D. T.; COELHO, A. S.. Questões Socioambientais no Alto Sertão Sergipano: Representações Sociais do Monumento Natural Grota do Angico, em Poço Redondo, Sergipe, pelas Comunidades Locais. In: SIMPÓSIO NACIONAL DE ÁREAS PROTEGIDAS. 3. Anais. Viçosa: UFV, 2014.

ALVES, R. R. N.; GONÇALVES, M. B. R.; VIEIRA, W.L.S.. Caça, uso e conservação de vertebrados no semiárido brasileiro. Tropical Conservation Science. v.5, p.394-416, 2012.

ARAUJO, M. A. R.. Unidades de Conservação no Brasil: da Republica à gestão de classe mundial. Belo Horizonte: SEGRAC, 2007.

BATTESINI, M. D.; SANTOS, C. Z. A. S.; NETO, J. O.. M. Publicações Acadêmicas das Unidades de Conservação no Estado de Sergipe, Brasil. Interciência, v.38, n.1, 2013.

BENSUSAN, N.. Conservação da Biodiversidade em Áreas Protegidas. ed 4.Rio de Janeiro: FGV, 2006.

BRAGHINI, C. R.; VILAR, J. W. C.. Gestão Territorial de Áreas Protegidas no Litoral Sergipano: primeiras incursões. Revista do Grupo de Pesquisa "Processos Identitários e Poder". v.01, n.1,2013.

BRASIL. Lei $\mathbf{n}^{\circ} \mathbf{9 . 9 8 5}$, de 18 de julho de 2000. Estabelece o sistema nacional de unidade de conservação. Brasília, 18 jul 2000.

CANINDÉ DE SÃO FRANCISCO. Decreto $n^{\circ}$ 041/2001. Cria o Parque Natural Municipal Lagoa do Frio. Canindé, 23 Out de 2001.

CASES, M. O.. Noções Básicas para elaboração de Planos de Manejo. Brasília: Instituto de Pesquisas Ecológicas, 2012.

CASTELLETTI, C. H. M.; SILVA, J. M. C.; TABARELLI, M.; SANTOS, A. M. M.. Quanto ainda resta da Caatinga? Uma estimativa preliminar. Brasília: Ministério do Meio Ambiente, 2004.

DIAS, E. S.. Conflitos socioambientais envolvendo as principais unidades de conservação do oeste paranaense. In: SIMPÓSIO BRASILEIRO DE GEOGRAFIA FÍSICA APLICADA. 8. Anais. Viçosa: UFMG, 2009.

DOURADO, S. P. C.. O Rural como fronteira do urbano: rodeios e vaquejadas nas interpretações do Brasil. Revista do centro de Educação e Letras da Unioeste. Foz do Iguaçu, v.15, p.52-69, 2013.

DOUROJEANNI, M. J., PÁDUA, M. T. J., Arcas à deriva: unidades de conservação do Brasil. 1 ed. Rio de Janeiro: TB, 2013.

FARIA, H. H.. Eficácia de Gestão de Unidades de Conservação gerenciadas pelo Instituto Florestal de São Paulo, Brasil. Dissertação (Mestrado) - Universidade de São Paulo, Presidente Prudente, 2004.

FARIA, H. H.; PIRES, A. S.. Atualidades na Gestão de Unidades de Conservação. Teodoro Sampaio: Instituto Florestal de São Paulo, 2007.

FARIA, H. H.; PIRES, A. S.; SÉRIO, F. C.. Gestão de Unidades de Conservação: conceituação e componentes básicos para a excelência do processo. Teodoro Sampaio: Instituto Florestal de São Paulo, 2007.

FLORES, S. S.; GRUBER, N. S.; MEDEIROS, R. M. V.. Gestão e conflitos em unidades de conservação: gestão estratégica e operacional para preservação ambiental. Porto Alegre: Universidade Federal do Rio Grande do Sul, 2009.

FONSECA, G. A. B.; PINTO, P. L.; RYLANDS, A. B.. Biodiversidade e Unidades de Conservação. São Paulo: Conservation International do Brasil, 1997. 
GELUDA, L.; YOUNG, C. E. F.. Financiando o Éden: Potencial econômico e limitações da compensação ambiental prevista na Lei do Sistema Nacional de Unidades de Conservação da Natureza. In: CONGRESSO NACIONAL DE UNIDADES DE CONSERVAÇÃO. 4. Anais. Curitiba, 2004.

GOMES, L. J.; SANTANA, V. B.; RIBEIRO, G. T.. Unidades de Conservação do Estado de Sergipe. Revista da Fapese. v.2, n.1, p.101-112, 2006.

HERCULANO, S.. Lá como cá: conflito, injustiça e racismo ambiental. In: SEMINÁRIO CEARENSE CONTRA O RACISMO AMBIENTAL. Anais. Fortaleza, 2006.

IBAMA. Parque Nacional Serra de Itabaiana: Levantamento da Biota. São Cristóvão: Universidade Federal de Sergipe, 2005.

IBAMA. Plano operativo de prevenção e combate aos incêndios florestais no parque nacional serra de Itabaiana. São Cristóvão: Universidade Federal de Sergipe, 2006.

IBAMA; WWF-BRASIL. Efetividade de Gestão das Unidades de Conservação Federais do Brasil: Implementação do método RAPPAM - Avaliação Rápida e Priorização da Gestão de Unidades de Conservação. Brasília, 2007.

ICMBIO. Proposta de Retificação e Atualização dos Limites da Reserva Biológica de Santa Isabel, no Estado de Sergipe. Brasília: ICMBIO 2010.

ICMBIO. Atlas da Fauna Brasileira Ameaçada de Extinção em Unidades de Conservação Federais. Brasília: ICMBIO, 2011.

KOBAYASHI, S.; LANGGUTH, A.. A new species of titi monkey, Callicebus Thomas, from north-eastern Brazil (Primates, Cebidae). Revista Brasileira de Zoologia, v.16, p.531-551, 1999.

KORNIJEZUK, N. B. S.. Cultura e biodiversidade: uma comparação entre a gestão do Parque Nacional do Cabo Orange, no Brasil, e a do Parque Nacional da Vanoise, na França. Tese (Doutorado em Desenvolvimento Sustentável) - Universidade de Brasília, Brasília, 2012.

LANDIM, M. F.; FONSECA, E. L.. A Mata Atlântica de Sergipe - Diversidade Florística, Fragmentação e Perspectivas de Conservação. In: CONGRESSO DE ECOLOGIA DO BRASIL. 8. Anais. Caxambu, 2007.

LEAL, I. R.; SILVA, J. M. C.; TABARELLI, M.; LACHER JUNIOR, T.. Mudando o curso da conservação da biodiversidade na Caatinga do Nordeste do Brasil. Megadiversidade, v.1, p.139-146, 2005.

LEMOS DE SÁ, R.. Unidades de conservação: espaços ameaçados ou áreas protegidas. Brasília: Relatório Técnico, 2000.

LIMA, G. S.; RIBEIRO, G. A.; GONÇALVES, W.. Avaliação da Efetividade de Manejo das Unidades de Conservação de Proteção Integral em Minas Gerais. Revista Árvore. Viçosa, v.29, n.4, p.647-653, 2005.

MEDEIROS, R.; IRVING, M.; GARAY, I.. A Proteção da Natureza no Brasil: Evolução e Conflitos de um Modelo em Construção. Revista de Desenvolvimento Econômico. Salvador, v.6, n.9, 2004

MELO, E. A.; ANDRADE, A. B.; SANTANA, M. C.. A Proteção dos Recursos Naturais da Reserva Biológica Santa Isabel: O papel das populações locais. Ambivalências: Revista do Grupo de Pesquisa "Processos Identitários e Poder"- GEPPIP. v.01, n.1, 2013.

MITTERMEIER, R. A.; GIL, P. R.; HOFFMANN, M.; PILGRIM, J.; BROOKS, T.; MITTERMEIER, C. G.; LAMOUREX, J.; FONSECA, G. A. B.. Hotspots Revisitados: as regiões biologicamente mais ricas e ameaçadas do planeta. Brasilia: Conservação Internacional, 2005.

MMA. Avaliação e identificação de áreas e ações prioritárias para a conservação, utilização sustentável e repartição dos benefícios da biodiversidade nos biomas brasileiros. Brasília, 2002.

OLIVEIRA, I. S. S.; GOMES, L. J.; SANTOS, J.. Proposta de Monitoramento dos Impactos do Ecoturismo no Parque Nacional Serra de Itabaiana, Sergipe. Revista Nordestina de Ecoturismo, Aquidabã , v.2, n.1, p. 6-24, 2009. 
OLIVEIRA, A. C. C. A.; SOUZA, R. M.. Ecodinâmica dos Sistemas dunares do município de Pirambu, Litoral Norte de Sergipe. Sociedade e Território, Natal, v.23, n. 2, p.2-20, 2011.

OLIVEIRA, T. H.. Parque Nacional Grande Sertão Veredas: o papel da população tradicional na conservação e nas decisões políticas sobre os rumos dos seus territórios naturais. Trabalho de Conclusão de Curso (Graduação) - Universidade de Brasília, Brasília, 2013.

PRIMACK, R. B.; RODRIGUES, E.. Biologia da Conservação. Londrina: ed. Planta, 2001.

PORTELA, S. V. S.; SCHLAEFLI, C. R. C.. A Contribuição das Reservas Particulares para a conservação do Bioma Caatinga. Viçosa: Manejo e Conservação de Áreas Protegidas, 2014.

RIBEIRO, R. F.. Introdução à questão metodológica. Rio de Janeiro: IBASE, 1995.

RINALDI, R. R. P.. Avaliação da Efetividade de Manejo em seis unidades de conservação do município do Rio de Janeiro (RJ). Viçosa: UFV, 2005.

ROCHA, L. G. M.; DRUMMOND, J. A.; GANEM, R. S.. Parques Nacionais Brasileiros: Problemas Fundiários e Alternativas Para a Sua Resolução. Revista de Sociologia e Política. v.18, n.36, p.205-226, 2010.

RYLANDS, A. B.; BRANDON, K.. Unidades de Conservação Brasileiras. Revista Megadiversidade. v.1, n.1, 2005.

SALMONA, Y. B.; RIBEIRO, F. F.; MATRICARDI, E. A. T.. Parques "no papel" conservam? O caso do Parque dos Pirineus em Goiás. Boletim Goiano de Geografia (Online), Goiânia, v.34, n.2, p.295-310, 2014.

SANTOS, A. F.; ANDRADE, J. A.. Delimitação e regionalização do Brasil Semi-Árido - Sergipe. São Cristóvão: Universidade Federal de Sergipe, 1992.

SANTOS, M. N. L.; SANTOS, M. C. L.. O Litoral Sergipano e a Opção pelo Turismo. São Cristóvão: Universidade Federal de Sergipe, 2013.

SEMARH. Plano de Manejo do Refúgio de Vida Silvestre Mata do Junco. Aracaju: SEMARH, 2011a.

SEMARH. Plano de Manejo do Monumento Natural Grota do Angico. Aracaju: SEMARH, 2011b.

SILVA, M, S, F.; SOUZA, R, M.. O Potencial fitogeográfico de Sergipe: uma abordagem a partir das unidades de conservação de uso sustentável. Scientia Plena, v 5, n.10, 2009.

SILVA, M. S. F.; SOUZA, R. M.. Áreas de proteção ambiental em Sergipe: perspectivas e desafios face aos conflitos territoriais decorrentes do uso dos recursos naturais. In: ENCONTRO NACIONAL DOS GEÓGRAFOS. 4. Anais. Porto Alegre, 2010.

SILVA, R. B. A.; ARAUJO, H. M. C. C.; PEREIRA, T. F.. Áreas Protegidas e Recursos Humanos: realidades, desafios e perspectivas, no contexto do Instituto Chico Mendes de Conservação da Biodiversidade ICMBio. Gestão, Pesquisa e Conservação em Áreas Protegidas. Viçosa, v.1, p.230, 2012.

SILVA, M. S. F.; SOUZA, R. M.. Territórios Protegidos e Arenas de Conflito nas Unidades de Conservação de Uso Sustentável em Sergipe, Brasil. Revista Electrónica de Geografia y Ciencias Sociales. Barcelona, n.445, 2013.

SILVA, A. C. C.; PRATA, A. P. N.; SOUTO, L. S.; MELLO, A. A.. Aspectos de Ecologia de Paisagem e Ameaças à Biodiversidade em uma Unidade de Conservação na Caatinga, em Sergipe. Revista Árvore. Viçosa, v.37, n.3, p.479-490, 2013.

SOBRAL, I. S.; SANTANA, R. K. O.; GOMES, L. J.; COSTA, M.; RIBEIRO, G. T.; SANTOS, J. R.. Avaliação dos Impactos Ambientais no Parque Nacional Serra de Itabaiana (SE). Revista Caminhos de Geografia. Uberlândia, v.8, n. 24, 2007.

SOUZA, I. A.; FERREIRA, D. J. S.; COELHO, A. S.. Levantamento Biológico dos Planos de Manejo de duas Unidades de Conservação de Proteção Integral do Estado de Sergipe. In: SIMPÓSIO NACIONAL DE ÁREAS PROTEGIDAS. 3. Anais. Viçosa: UFV, 2014. 
SOUZA, J. S.. Uma análise das memórias do cangaço na "dança de cabra macho". IN: SEMINÁRIO DE ESTUDOS CULTURAIS, IDENTIDADES E RELAÇÕES INTERÉTNICAS. 3. Anais. São Cristóvão: UFS, 2013.

TABARELLI, M.; GASCON, C.. Lições da Pesquisa sobre Fragmentação: aperfeiçoando políticas e diretrizes de manejo para a conservação da Biodiversidade. Revista Megadiversidade. v.1, n.1, 2005.

TERBORGH, J.; SCHAIK, C. V.. Por que o mundo necessita de parques? Curitiba: Universidade Federal do Paraná, 2002.

ERVIN, J.. WWF: Metodologia para Avaliação Rápida e a Priorização do Manejo de Unidades de Conservação (RAPPAM). Suíça: Gland, 2003. 